\title{
ELECTROCHEMICAL AND COMPUTATIONAL STUDY OF COPPER (II) ALKYLPYRAZOLONE BASED ENAMINE COMPLEX
}

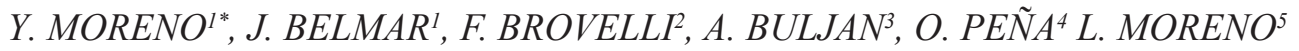 \\ ${ }^{\prime}$ Facultad de Ciencias Químicas, Universidad de Concepción, Casilla 160-C, Concepción, Chile. \\ ${ }^{2}$ Depto. Cs. Basicas, Universidad de Concepción, Los Angeles, Chile. \\ ${ }^{3}$ Facultad de Ciencias Químicas (Grupo QTC), Universidad de Concepción, Concepción, Chile. \\ ${ }^{4}$ Sciences Chimiques de Rennes. UMR-CNRS 6226. Université de Rennes 1, Av. du Général Leclerc, 35042 Rennes cedex, France. \\ ${ }^{5}$ Depto. Cs. Básicas, Facultad de Ciencias, Universidad del Bío Bío, Casilla 447, Chillán, Chile. \\ (Received: December 26, 2007 - Accepted: May 23, 2008)
}

\begin{abstract}
The cyclic voltammograms (CV) of the copper complex $\mathrm{CuL}_{2}, \mathrm{~L}_{\mathrm{C}} \mathrm{C}_{19} \mathrm{H}_{26} \mathrm{~N}_{3} \mathrm{O}$ [1-(n-hexyl)-3-methyl-4-[1-phenylaminopropylidene]-2-pyrazolin-5-one] have been studied. The $\mathrm{CV}$ profiles of $\mathrm{CuL}_{2}$ show one or two reduction and oxidation wave. The energy level corresponding to the highest occupied molecular orbital (HOMO) and the lowest unoccupied molecular orbital (LUMO) of $\mathrm{CuL}_{2}$ have been determined experimentally from the first oxidation and reduction onset potential, respectively. These values were also estimated from Density Functional calculations. The electrochemical energy gap deduced from these measurements $\left(\mathrm{E}_{\mathrm{g}} \sim 1.03 \mathrm{eV}\right)$ agrees quite well with the theoretical value.
\end{abstract}

\section{INTRODUCTION}

Pyrazolones are an important family of organic compounds. ${ }^{1,2}$ They have been widely studied as a consequence of their numerous applications $\mathrm{s}^{3-6}$ and in particular as chelating agents for solvent extraction of various metal ions..$^{7,8}$ Schiff bases ${ }^{9}$ and enamines derived from pyrazolones ${ }^{10}$ are known but they present solubility problems. To overcome this lack of solubility, convenient syntheses of 1-n-alkyl derivatives of pyrazolones were reported a few years ago. ${ }^{11}$

The electrochemical methods are very important tools to characterize organic or inorganic systems. In this field, cyclic voltammetry (CV) is recognised as an important technique for measuring band gaps, electron affinities (i.e. the energy of LUMO, $\varepsilon_{\text {LUMO }}$ ) and ionization potential (i.e. the energy of HOMO, $\left.\varepsilon_{\text {номо }}\right)^{12-14}$ In this case, the oxidation process corresponds to removal of an electron from the HOMO energy level whereas the reduction cycle corresponds to electron addition to the LUMO.

Electrochemical studies using metal complexes with ligand based on 1-phenylpyrazolone Schiff bases have been reported. ${ }^{15}$ However the electrochemical behaviour of 1-alkylpyrazolone was not totally established, ${ }^{16}$ since it was not achieved to assign the nature of the voltammetric peaks observed.

In the present work we have determined several electronic properties of a copper (II) alkylpyrazolone based enamine complex (scheme 1) by electrochemical measurements $\left(\varepsilon_{\mathrm{LUMO}}, \varepsilon_{\text {номо }}\right.$, and $\left.\mathrm{E}_{\mathrm{g}}\right)$. Furthermore we have compared the experimental with theoretical values obtained from densityfunctional calculations. For this we have calculated the electron density frontier orbitals and the natural charges. ${ }^{17}$

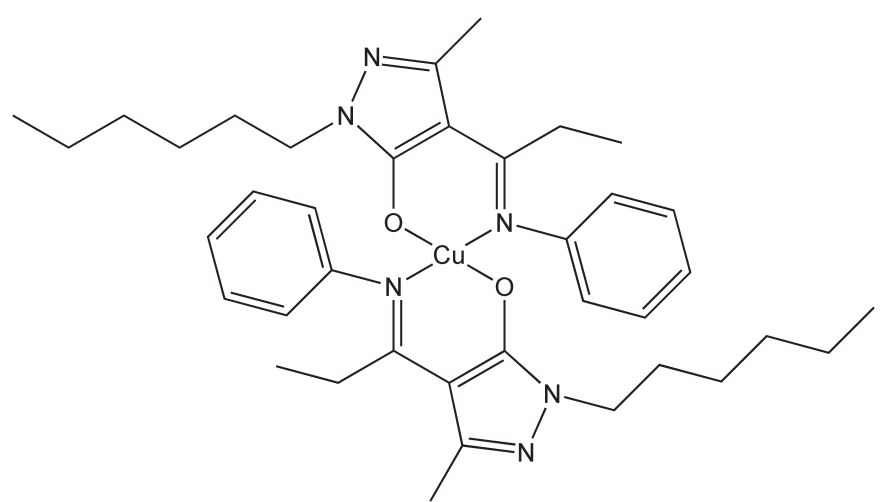

Scheme 1: Molecular structure of copper (II) alkylpyrazolone based enamine complex.

\section{EXPERIMENTAL}

\section{Copper complex synthesis}

The copper (II) complex shown in the scheme 1 was prepared from 0.1000 $\mathrm{g}(0.32 \mathrm{mmol})$ of protonated ligand $\mathrm{HL}\left(\mathrm{C}_{10} \mathrm{H}_{27} \mathrm{~N}_{3} \mathrm{O}\right)$ and $0.032 \mathrm{~g}(0.16 \mathrm{mmol})$ of $\mathrm{Cu}\left(\mathrm{CH}_{3} \mathrm{COO}\right)_{2} \cdot \mathrm{H}_{2} \mathrm{O}$ dissolved in ethanol $(10 \mathrm{~mL})$ and heated under reflux for $1 \mathrm{~h}$. The solution was then evaporated to a final volume of $5 \mathrm{ml}$ and allowed to cool at room temperature. The solid was filtered off and crystallized by slow evaporation from a chloroform-hexane mixture, $1: 1 v / v$ (yield 0.08g, 73\%; m.p. $396(2) K^{18,19}$

\section{Electrochemical setup}

The experimental method to carry out the cyclic voltammetry (CV) has been described in the literature. ${ }^{20,21} \mathrm{~A}$ glassy carbon disc of $0.07 \mathrm{~cm}^{2}$ geometric area was used as working electrode. The reference electrode was $\mathrm{Ag} / \mathrm{AgCl}$ in solution of tetraethylammonium chloride $\left(\mathrm{Et}_{4} \mathrm{NCl}\right)$. The potential was adjusted to $0.197 \mathrm{~V}$ versus normal hydrogen electrode (NHE). ${ }^{22}$ Platinum gauze was used as counter-electrode.

Prior each experiment, the working electrode was polished with alumina slurry (particle size $0.3 \mu \mathrm{m}$ ) and the rinsed with bidestilled water and acetonitrile. Acetonitrile anhydrous (Aldrich Chemical $\mathrm{Co}$ ) was used as solvent and it was manipulated with syringes. Tetrabutylammonium perchlrorate $\left(\mathrm{TBAClO}_{4}\right)$ (Aldrich Chemical Co) was used as supporting electrolyte and it was dried under vacuum at $40^{\circ} \mathrm{C}$ for $24 \mathrm{~h}$

The electrochemical profiles were obtained from $0.001 \mathrm{M}$ copper complex and ligand solutions containing $0.1 \mathrm{M}$ supporting electrolyte at $100 \mathrm{mV} / \mathrm{s}$ scanning rate.

All solutions were kept under flowing argon during 30 min before each experiment. The gas flux was inverted to keep an inert atmosphere over the solution while the electrochemical perturbation was applied. The electrochemical data were recorded in a BAS CV-50W system.

\section{Computational calculations}

The calculations were performed by using effective core pseudopotentials (ECP) basis set on the copper atom, and the standard basis set $6-31 \mathrm{G}^{* *}$ for carbon, oxygen, nitrogen, and hydrogen atoms. ${ }^{23} \mathrm{The} \mathrm{Ar}$ core electrons of $\mathrm{Cu}$ were replaced by an ECP and DZ quality Hay and Wadt Los Alamos ECP basis set (LANL2DZ) ${ }^{24}$ was used for the valence electrons. The LANL2DZ basis set has been successfully used in calculation on metalloporphyrins and derivatives and transition metal complexes. ${ }^{25,26}$

Electron correlation effects were considered employing density functional theory (DFT) methods, which have been considered as a practical and effective computational tool, especially for organometallic compounds. ${ }^{27,28}$ Among these functional procedures, the most reliable approximation is often thought to be the hybrid HF/DFT method using a combination of the three nonlocal correlation functional; this method is called B3LYP. ${ }^{29}$ GAUSSIAN 03W package ${ }^{30}$ was used in the calculations. The geometry optimization was carried out with the unrestricted B3LYP functional ${ }^{29,31}$ and using the above basis sets. The molecular structures were fully optimized in gas phase, without symmetry 
restrictions, and compared with single crystal X-ray structure. ${ }^{19,32}$ To plot the electron densities of HOMO and LUMO levels, we used the MacSpartanPro software. ${ }^{33}$ The natural population analysis was performed using the NPA keyword implemented in the GAUSSIAN $03 \mathrm{~W} .{ }^{34}$

\section{RESULTS AND DISCUSSION}

\section{Electrochemical characterization}

The electrochemical behaviour of the $\mathrm{CuL}_{2}$ complex and the ligand $\mathrm{L}$ were studied by cyclic voltammetry (CV) (see figure 1 ). The CVs profiles were performed in the potential range of -1.60 to $+1.35 \mathrm{~V}$. The $\mathrm{CuL}_{2}$ and $\mathrm{L}$ profiles in acetonitrile show one or two reduction and oxidation waves depending on the potential limits imposed.

For the ligand, two irreversible anodic peaks were observed at +0.775 and $+1.250 \mathrm{~V}$ in the anodic scan $(-1.025$ and $-1.540 \mathrm{~V}$ for the cathodic scan). Other authors have studied similar enamines ligands (e.g. 1-(n-hexyl)-3-methyl-5pyrazolone $\left.{ }^{16}\right)$ and they found only one irreversible anodic peak. In our situation, if the anodic potential limit is increased, another peak can be observed. This feature is more representative of a molecular system with several redox sites because the ligand used in this study is a more reactive enamine. On the other hand, the copper (II) complex shows anodic peaks potentials at +0.590 and $+0.690 \mathrm{~V}$ for the anodic scan and -0.850 and $-1.100 \mathrm{~V}$ for the cathodic scan respectively. The onset potentials $\left(\mathrm{E}_{\mathrm{on}}\right)$ for the first oxidation and reduction waves are situated at $+0.416 \mathrm{~V}$ and $-0.615 \mathrm{~V}$, respectively. The onset potentials were obtained from the intersection of the two tangents drawn at the raising current and the background charging current of the CVs. The feature found is very similar to that found for the ligand; nevertheless anodic peaks appear at a less anodic potential and, in addition, both peaks correspond only to the ligand.
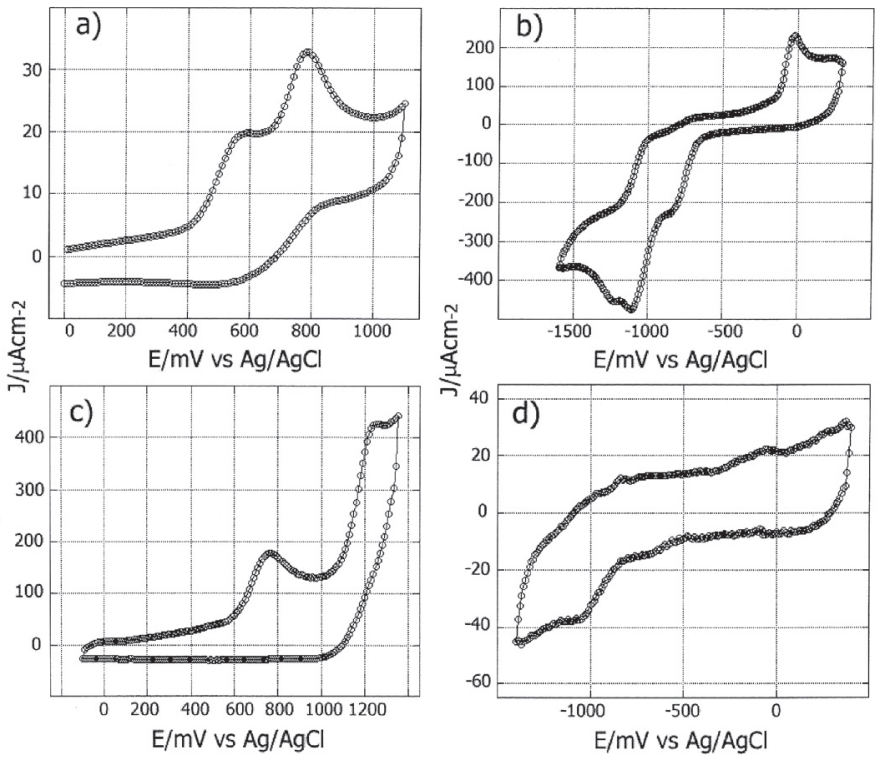

Figure 1. Cyclic voltammogram of $\mathrm{CuL}_{2}$ and $\mathrm{L}$ in acetonitrile: $(\mathrm{a}, \mathrm{b})$ anodic and cathodic profiles of copper complex. (c, d) anodic and cathodic profiles of ligand.

An important aspect to emphasize is that during the formation of the copper complex a change in the ligand structure takes place, which allows the formation of new bonds with the copper (II) ion. In order to make a correct allocation of the observed electrochemical phenomena it is necessary to calculate the energy of the frontiers orbital in the complex so as to determine the most reactive sites in this molecule.

As a first approach, it is possible to determine the energy of the frontier orbital from the electrochemical parameters. The HOMO and LUMO energies can be determined from the first oxidation and reduction onset potentials, respectively. The potential difference can be used to estimate the energy gap of the copper complex, that is, the $\mathrm{E}_{\mathrm{g}}=\varepsilon_{\mathrm{LUMO}}-\varepsilon_{\text {номо }}$. The energy level of the normal hydrogen electrode (NHE) is situated $4.5 \mathrm{eV}$ below the zero vacuum energy level. ${ }^{35}$ From this value and the redox potential of the reference electrode used in the present work $\mathrm{Ag} / \mathrm{AgCl}(0.197 \mathrm{~V})$, a simple relation can be written which allows estimating both energy values: ${ }^{36,37}$

The experimental energies values of HOMO and LUMO levels for $\mathrm{CuL}_{2}$ are -4.28 and $-5.31 \mathrm{eV}$ respectively; therefore the band gap estimated from the electrochemical measurements is $1.03 \mathrm{eV}$ (table 1). The electrochemical energy gap deduced from these measurements is mayor than calculated theoretical value. This result is not strange, because it is well-known that the calculated band gap in many cases does not agree with the experimental value. ${ }^{38,39}$

Table 1: Electrochemical parameters for $\mathrm{L}$ and $\mathrm{CuL}_{2}$ obtained from cyclic voltammetry

\begin{tabular}{|c|c|c|}
\hline System & $\begin{array}{c}\text { First anodic peak potential } \\
(\mathrm{mV})\end{array}$ & $\begin{array}{c}\text { First cathodic peak } \\
\text { potential }(\mathrm{mV})\end{array}$ \\
\hline $\mathrm{L}$ & 775 & -1025 \\
\hline $\mathrm{CuL}_{2}$ & 590 & -850 \\
\hline & Anodic onset potential & Cathodic onset potential \\
\hline $\mathrm{CuL}_{2}$ & 416 & -615 \\
\hline \multicolumn{2}{|c|}{1.03} \\
\hline $\mathrm{CuL}_{2}$ & \multicolumn{2}{|c|}{ Experimental gap energy (eV) } \\
\hline
\end{tabular}

\section{Computational calculation}

As a first approach we have carried out the geometry optimization of the ligand $(\mathrm{L})$ and the complex $\left(\mathrm{CuL}_{2}\right)$. However, during the geometric optimization process, convergence problems took place, increasing the calculation time; furthermore, it was not found a minimum energy conformation in both cases. This is due to the great number of conformers that can exist in ligand and complex respectively. Due to this, in both the ligand and the complex, we have eliminated the aliphatic flexible chains and they were replaced by methyl groups, this allowed to avoid the problem of convergence and to find a minimum (see scheme 2).

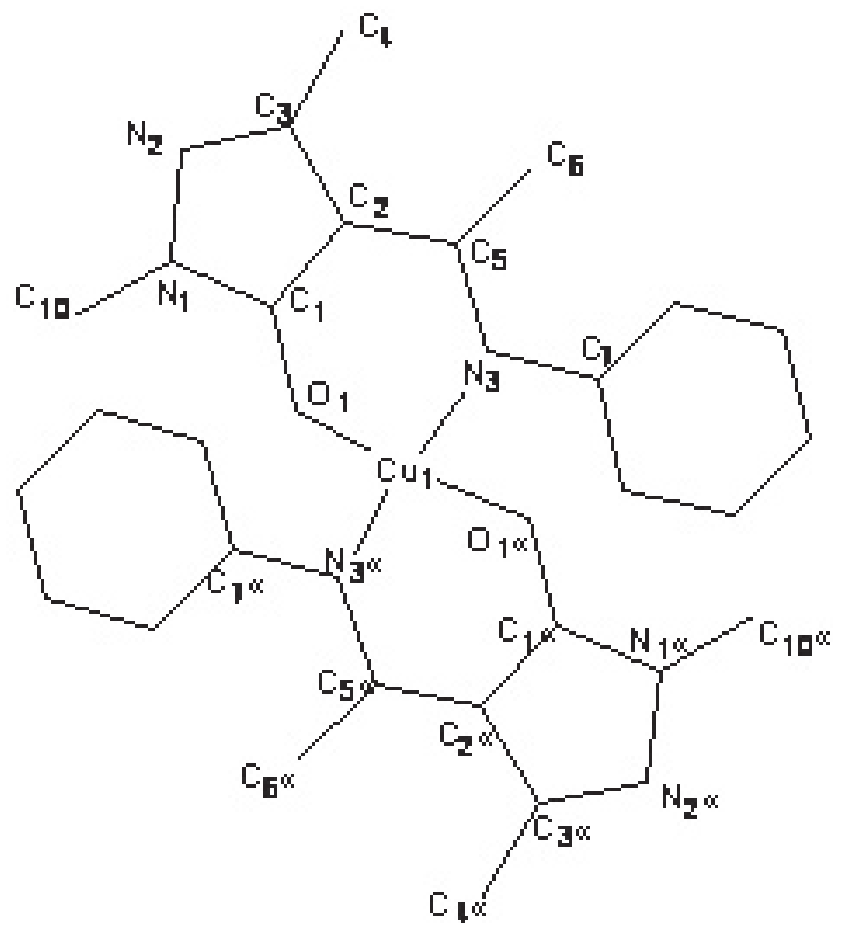

Scheme 2: Molecular structure of model used to study the $\mathrm{CuL}_{2}$ complex.

At this stage, a new problem was observed: the geometry around the copper ion in the optimized model invariably evolved toward a distorted tetrahedral. However the experimental geometry showed a plane square coordination around copper ion, without solvent molecules in the axial positions. To make modellization more realistic in terms of coordination geometry, two molecules of acetonitrile were included at the axial positions. From now on, we will refer 
to this new model as $\mathrm{CuL}_{2} \mathrm{~S}_{2}\left(\mathrm{~S}=\mathrm{CH}_{3} \mathrm{CN}\right)$. In this way, in the optimization process we considered the effect of two solvent molecules on the equilibrium geometric parameters. We consider that this modification should not affect significantly the validity of the electrochemical parameters. The equilibrium geometries of the ligand $\mathrm{L}$ and of the complex $\mathrm{CuL}_{2} \mathrm{~S}_{2}$ obtained through DFT calculations were compared with those reported in literature. ${ }^{19,32}$ Table 2 shows values of bond length for the optimized ligand model employed in this study, which are in agreement with the experimental data obtained by $\mathrm{X}$ ray diffraction (XRD). In addition table 2 shows the values of the optimized geometric parameters for the $\mathrm{CuL}_{2} \mathrm{~S}_{2}$ complex model. The results are quite close to the values reported in the literature ${ }^{32}$ since the errors found in bond distances and angles are less than $0.2 \%$, e.g. $0.04 \AA$ and 0.5 degrees.

Table 2: Comparison between single crystal X-ray diffraction (XRD) measurements and DFT calculations of ligand model (L) and copper (II) complex with two acetonitrile axial molecules $\left(\mathrm{CuL}_{2} \mathrm{~S}_{2}\right.$ model).

\begin{tabular}{|c|c|c|c|c|c|}
\hline \multicolumn{3}{|c|}{ Ligand } & \multicolumn{3}{|c|}{ Copper (II) Complex } \\
\hline Distance & XRD & DFT & Distance & XRD & DFT \\
\hline $\mathrm{O} 1-\mathrm{C} 1$ & $1.253(2)$ & 1.251 & $\mathrm{Cu} 1-\mathrm{O} 1$ & $1.879(2)$ & 1.875 \\
\hline $\mathrm{N} 1-\mathrm{C} 1$ & $1.355(2)$ & 1.370 & $\mathrm{Cu} 1-\mathrm{O} 1^{\prime}$ & $1.879(2)$ & 1.877 \\
\hline $\mathrm{N} 1-\mathrm{N} 2$ & $1.385(2)$ & 1.385 & Cu1-N3 & $2.036(3)$ & 2.038 \\
\hline $\mathrm{N} 1-\mathrm{C} 10$ & $1.452(3)$ & 1.443 & Cu1-N3' & $2.036(3)$ & 2.040 \\
\hline $\mathrm{N} 2-\mathrm{C} 3$ & $1.312(2)$ & 1.311 & $\mathrm{O} 1-\mathrm{C} 1$ & $1.282(4)$ & 1.285 \\
\hline N3-C5 & $1.330(2)$ & 1.354 & N3-C5 & $1.317(4)$ & 1.314 \\
\hline N3-C8 & $1.434(2)$ & 1.411 & $\mathrm{C} 2-\mathrm{C} 5$ & $1.420(5)$ & 1.419 \\
\hline $\mathrm{C} 1-\mathrm{C} 2$ & $1.438(3)$ & 1.466 & $\mathrm{C} 1-\mathrm{C} 2$ & $1.409(5)$ & 1.409 \\
\hline $\mathrm{C} 2-\mathrm{C} 5$ & $1.394(2)$ & 1.391 & $\mathrm{C} 2-\mathrm{C} 3$ & $1.430(5)$ & 1.429 \\
\hline $\mathrm{C} 2-\mathrm{C} 3$ & $1.439(2)$ & 1.449 & $\mathrm{~N} 2-\mathrm{C} 3$ & $1.314(4)$ & 1.314 \\
\hline $\mathrm{C} 3-\mathrm{C} 4$ & $1.477(3)$ & 1.500 & N1-N2 & $1.375(4)$ & 1.376 \\
\hline \multicolumn{6}{|c|}{ Copper (II) Complex } \\
\hline Angle & XRD & DFT & Angle & XRD & DFT \\
\hline $\begin{array}{l}\text { O1-Cu1- } \\
\text { O1' }\end{array}$ & $180.00(7)$ & 179.8 & $\begin{array}{l}\text { C1-O1- } \\
\text { Cu1 }\end{array}$ & $122.5(2)$ & 122.4 \\
\hline $\begin{array}{l}\text { O1-Cu1- } \\
\text { N3 }\end{array}$ & $92.24(11)$ & 92.4 & $\begin{array}{l}\text { O1-C1- } \\
\text { C2 }\end{array}$ & $131.7(3)$ & 131.7 \\
\hline $\begin{array}{l}\text { O1'-Cu1- } \\
\text { N3 }\end{array}$ & $87.76(11)$ & 87.8 & $\begin{array}{l}\text { C1-C2- } \\
\text { C5 }\end{array}$ & $122.8(3)$ & 122.7 \\
\hline $\begin{array}{l}\text { O1-Cu1- } \\
\text { N3 }\end{array}$ & $87.76(11)$ & 87.6 & $\begin{array}{l}\text { C2-C5- } \\
\text { N3 }\end{array}$ & $120.3(6)$ & 120.8 \\
\hline $\begin{array}{l}\text { O1'-Cu1- } \\
\text { N3' }\end{array}$ & $92.24(11)$ & 92.2 & $\begin{array}{l}\text { C5-N3- } \\
\text { Cu1 }\end{array}$ & $126.6(2)$ & 126.5 \\
\hline $\begin{array}{l}\text { N3-Cu1- } \\
\text { N3' }\end{array}$ & $180.0(13)$ & 179.9 & & & \\
\hline
\end{tabular}

Once the geometries for the ligand $\mathrm{L}$ and the $\mathrm{CuL}_{2} \mathrm{~S}_{2}$ complex were optimized, we have calculated the electron density maps of HOMO and LUMO states for these models (see figure 2). Also, we calculated the electron density maps of the $\mathrm{CuL}_{2}$ complex, our aim being to observe the effect of solvent molecules $\left(\mathrm{CH}_{3} \mathrm{CN}\right)$ on the electronic properties of the complex.

The electron density maps suggest that the oxidation of the ligand involves mainly the pirazolone moiety (see figure 2a). The presence of several reactive sites in this molecule must be due to the presence of conjugated double bonds, which influences the distribution of the electronic density (the HOMO level is delocalized over several atoms). In the copper complex (figure 2c), the situation is very similar to that of the ligand; however it exists a location of the electronic density between the $\mathrm{C} 1, \mathrm{C} 2, \mathrm{~N} 2, \mathrm{C} 1$ ', $\mathrm{C} 2$ ' and $\mathrm{N} 2$ ' atoms. This location must be mainly the effect of the copper ion. The electron density map for the complex which includes the two acetonitrile axial molecules is a little different, because the localization is now over $\mathrm{C} 3, \mathrm{C} 5, \mathrm{C} 3$ ' and $\mathrm{C} 5$ ' atoms.

For the LUMO level the electronic density maps indicate that these molecules may suffer a nucleophilic addition to $\alpha, \beta$ unsaturated double bonds. However the effect of the copper ion has modified the distribution of the MO and it participates in the LUMO. Under these features it is possible to identify two oxidation processes that involve only ligand double bonds carbon-carbon, carbon-nitrogen and carbon-oxygen. In the reduction process, besides the ligand double bonds, it also involves the metal ion; in this case three reduction processes will exist, two for the ligand and one for the metal ion.

Table 3 shows the atomic charges from the natural population analysis (NPA) ${ }^{17}$ for ligand $\mathrm{L}$ and $\mathrm{CuL}_{2}$ and $\mathrm{CuL}_{2} \mathrm{~S}_{2}$ model complexes. We have included natural charges associated to atoms that are directly bonded to copper ion. The calculated charge on the copper ion is lower than the formal charge +2 . It results from charge donation from the nitrogen and oxygen atoms of the ligand.

Table 3: Atomic charges from the natural population analysis (NPA) for the model complexes: $\left(\mathrm{CuL}_{2} \mathrm{~S}_{2}\right),\left(\mathrm{CuL}_{2}\right)$, and the ligand $(\mathrm{L})$.

\begin{tabular}{|c|c|c|c|}
\hline Atom & $\mathrm{CuL}_{2} \mathrm{~S}_{2}$ & $\mathrm{CuL}_{2}$ & $\mathrm{~L}$ \\
\hline $\mathrm{Cu} 1$ & 1.26 & 1.13 & - \\
\hline $\mathrm{O} 1$ & -0.81 & -0.83 & -0.68 \\
\hline $\mathrm{C} 1$ & 0.64 & 0.64 & 0.63 \\
\hline $\mathrm{C} 2$ & 0.17 & 0.19 & 0.20 \\
\hline $\mathrm{C} 3$ & -0.26 & -0.26 & -0.29 \\
\hline $\mathrm{C} 5$ & 0.23 & 0.24 & 0.33 \\
\hline N3 & -0.68 & -0.69 & -0.57 \\
\hline $\mathrm{O} 1^{\prime}$ & -0.81 & -0.83 & - \\
\hline $\mathrm{C}^{\prime}$ & 0.64 & 0.64 & - \\
\hline $\mathrm{C} 2^{\prime}$ & 0.17 & 0.18 & - \\
\hline $\mathrm{C} 3^{\prime}$ & -0.26 & -0.26 & - \\
\hline $\mathrm{C} 5^{\prime}$ & 0.23 & 0.24 & - \\
\hline N3' & -0.68 & -0.70 & - \\
\hline
\end{tabular}

The atomic charge presented by the atoms $\mathrm{O} 1$ and $\mathrm{N} 3$ in the ligand decreases after complex formation. This is because oxygen and nitrogen have the electron-donor's behavior on the copper ion (an electrophilic site). For the copper complex the negative region involved by the bonds of the ligand and the positive region is located in the metal ion and over $\mathrm{C} 1$ and $\mathrm{C} 5$. These results are coherent with those obtained with HOMO and LUMO electron densities.

The band gap energy values calculated for $\mathrm{CuL}_{2} \mathrm{~S}_{2}$ and $\mathrm{CuL}_{2}$ from DFT UB3LYP/6-31G**/LANL2DZ level theory calculations are 0.66 and $0.61 \mathrm{eV}$ respectively. 

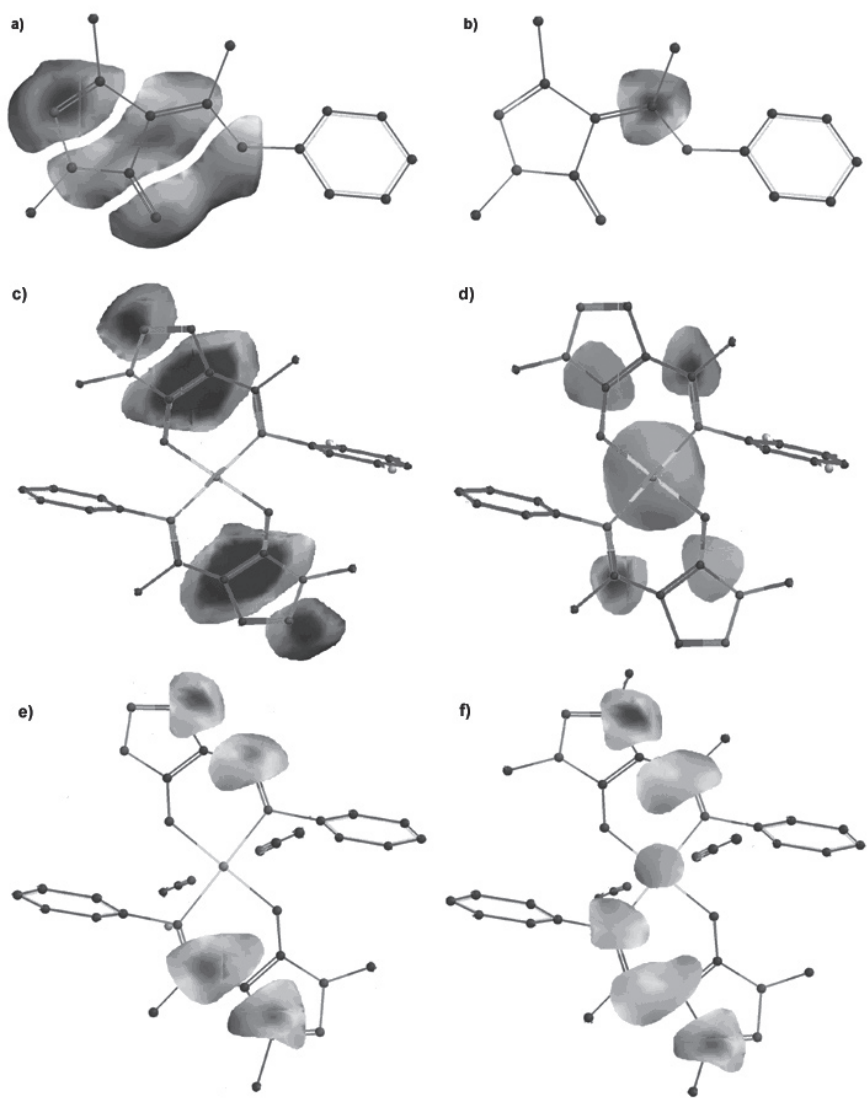

Figure 2. Electronic densities maps of HOMO and LUMO levels for copper complexes and ligand obtained from B3LYP/6-31G**/LANL2DZ calculations: (a, b) ligand; (c, d) $\mathrm{CuL}_{2}$ and $(\mathrm{e}, \mathrm{f}) \mathrm{CuL}_{2} \mathrm{~S}_{2}$.

\section{CONCLUSION}

Cyclic voltammograms of copper complex $\mathrm{CuL}_{2}, \mathrm{~L}: \mathrm{C}_{19} \mathrm{H}_{26} \mathrm{~N}_{3} \mathrm{O}[1-(\mathrm{n}-$ hexyl)-3-methyl-4-[1-phenylaminopropylidene]-2-pyrazolin-5-one] show one or two reduction and oxidation waves. The electrochemical oxidation process involves only ligand double bond but the reduction involves the ligand and also the copper ion. The energy levels corresponding to HOMO and LUMO levels have been determined experimentally from the first oxidation and reduction onset potential respectively, and their values were estimated using DFT UB3LYP/6-31G**/LANL2DZ level theory. The electrochemical energy gap deduced from these measurements $(\mathrm{E} \sim 1.03 \mathrm{eV})$ it is something different than the calculated theoretical value, although it falls inside the expected range.

\section{ACKNOWLEDGEMENTS}

The authors thank to DIUC 208.021.026-1.0 and FONDECYT 1040461 for the financial support and Spanish Research Council (CSIC) for providing us with a free-of-charge license to the CSD system.

\section{Supplementary data}

Supplementary data for this paper are available from the IUCr electronic archives (reference: OB1229)

\section{REFERENCES}

1. (a) R. H.Wiley and P. Wiley, Hetrocyclic Compounds, Interscience Publishers, New York, USA. 20 (1964); (b) J. Elguero, in Comprehensive Heterocyclic Chemistry: Pyrazoles and their Benzo Derivatives, eds. A. R. Katritzky and C. W. Rees, Pergamon Press, Oxford, UK. 5, 167-303 (1984); (c) J. Elguero, in Comprehensive Heterocyclic Chemistry II: Pyrazoles, eds. A. R. Katritzky, C. W. Rees and E. F. V. Scriven, Pergamon Press, Oxford, UK. Vol 3, 1-75 (1996); (d) M. H. Elnagdi, G. E. H. Elgemeie and
F. A. Abd-Elaal, Heterocycles. 23, 3121(1985).

2. M. L. Kutznetsov, A. I. Dement'ev and V. V. Zhornik, J. Mol. Struct. 45, 571(2001).

3. R. N. Brodgen, Drugs. 32, 60 (1996).

4. K. L. Kees, J. J. Fitzgerald, Jr., K. E. Steiner, J. F. Mattes, B. Mikau, T. Tosi, D. Mondoro and M. Caleb, J. Med. Chem. 39, 3920 (1996).

5. A. Gürzov, S. Demirayak, G. Capaan, K. Erol and K. Vural, Eur. J. Med. Chem. 35, 359 (2000).

6. K. Venkataraman, The Chemistry of Dyes, vol. 1,Academic Press, New York (1952).

7. C. Petinari, F. Marchetti, A. Cingolari, D. Leonesi, S. Troyanov and A. Drozov, J. Chem. Soc., Dalton Trans. 1555 (1999).

8. C. Petinari, F. Marchetti, A. Cingolari, D. Leonesi, S. Troyanov and A. Drozov, J. Chem. Soc., Dalton Trans. 831(2000).

9. (a) R. C. Maurya, D. D. Mishra and N. S. Rao, Polyhedron. 11, 2837 (1992); (b) N. S. Rao, M. N. Jaiswal, D. D. Mishra and R. C. Maurya, Polyhedron. 12, 2045 (1993); (c) N. S. Rao, D. D. Mishra and R. C. Maurya, Polyhedron. 13, 2653 (1994); (d) D. K. Dey, M. K. Saha, M. K. Das, N. Bhartiya, R. K. Bansal, G. Rosair and S. Mitra, Polyhedron. 18, 2687(1999).

10. L. N. Kurkovskaya, N. N. Shapet'ko, I. Y. Kvitko, Y. N. Koshelev and E. M. Sof'ina, Zh. Org. Khim. 9, 821(1973).

11. J. Bartulin, J. Belmar and G. Leon, Bol. Soc. Chil. Quim. 37, 13 (1992).

12. W. C. Chang, S. A. Jenekhe, Macromolecules. 28, 465 (1995).

13. R.Cervini, X. C. Li, G.W. Spencer, A.B. Holmes, S.C. Morath, R.H. Friend, Synthetic Metals. 84, 359 (1997).

14. Q. Zhang, Y. Li, M. Yang, Synthetic Metals. 146, 69 (2004).

15. (a) H. Barjesteh, J. Chakrabarti, J. Charalambous, Polyhedron. 15, 1323 (1996); (b) R.C. Maurya, D.D. Mishra, S. Rao, Polyhedron. 11, 2840 (1992).

16. F.R. Perez, L. Basáez, J. Belmar, P. Vanysek, J. Chil. Chem. Soc. 50, 575 (2005).

17. A. E. Reed, F. Weinhold, J. Chem. Phys. 78, 4066 (1983).

18. J. Belmar, F. Pérez, J. Alderete, C. Zúñiga, J. Braz. Chem. Soc. 16, 179 (2005).

19. J. Belmar, F. Pérez, Y. Moreno, R. Baggio, Acta Cryst. C60, 705 (2004).

20. F. Brovelli, M.A. del Valle, F.R. Díaz, J.C. Bernède, Bol. Soc. Chil. Quim. 46, 319 (2001).

21. R. Córdova, M. A. del Valle, H. Gómez, R. Schrebler, J. Electroanal. Chem. 377, 75 (1994).

22. G. East, M. A. del Valle, J. Chem. Ed. 77, 97 (2000).

23. W.J. Hehre, R. Ditchfield, J.A. Pople, J. Chem. Phys. 56, 2257 (1972).

24. P.J. Hay and W.R. Wadt, J. Chem. Phys. 82, 270 (1985).

25. G. Cárdenas-Jirón, J. Chil. Chem. Soc. 49, 101(2004).

26. V. Paredes-García, G.I. Cárdenas-Jirón, D. Venegas-Yazigi, J.H. Zagal, M. Paez, J. Costamagna, J. Phys. Chem. A. 109, 1196 (2005).

27. I.S. Ignatyev, H.F. Schaefer, R.B. King, S.T. Brown, J. Am. Chem. Soc. 122, 1984 (2000).

28. J.P. Kenny, H.F. Schaefer, R.B. King, Inorg. Chem. 40, 900 (2001).

29. A.D. Becke, J. Chem. Phys. 98, 5648 (1993).

30. Gaussian 03, Revision D.01, M. J. Frisch, G. W. Trucks, H. B. Schlegel, G. E. Scuseria, M. A. Robb, J. R. Cheeseman, J. A. Montgomery, Jr., T. Vreven, K. N. Kudin, J. C. Burant, J. M. Millam, S. S. Iyengar, J. Tomasi, V. Barone, B. Mennucci, M. Cossi, G. Scalmani, N. Rega, G. A. Petersson, H. Nakatsuji, M. Hada, M. Ehara, K. Toyota, R. Fukuda, J. Hasegawa, M. Ishida, T. Nakajima, Y. Honda, O. Kitao, H. Nakai, M. Klene, X. Li, J. E. Knox, H. P. Hratchian, J. B. Cross, V. Bakken, C. Adamo, J. Jaramillo, R. Gomperts, R. E. Stratmann, O. Yazyev, A. J. Austin, R. Cammi, C. Pomelli, J. W. Ochterski, P. Y. Ayala, K. Morokuma, G. A. Voth, P. Salvador, J. J. Dannenberg, V. G. Zakrzewski, S. Dapprich, A. D. Daniels, M. C. Strain, O. Farkas, D. K. Malick, A. D. Rabuck, K. Raghavachari, J. B. Foresman, J. V. Ortiz, Q. Cui, A. G. Baboul, S. Clifford, J. Cioslowski, B. B. Stefanov, G. Liu, A. Liashenko, P. Piskorz, I. Komaromi, R. L. Martin, D. J. Fox, T. Keith, M. A. Al-Laham, C. Y. Peng, A. Nanayakkara, M. Challacombe, P. M. W. Gill, B. Johnson, W. Chen, M. W. Wong, C. Gonzalez, and J. A. Pople, Gaussian, Inc., Wallingford CT, 2004.

31. C. Lee, W. Yang, G. Parr, Phys. Rev. B 37, 785 (1988).

32. F.R. Pérez, J. Belmar, C. Jiménez, Y. Moreno, R. Baggio, Acta Cryst. C61, M318-M320 (2005).

33. Wavefunction, Inc. 18401 Von Karman Avenue, Suite 370 Irvine, Ca 92612 USA.

34. A. Ree, L.A. Curtiss, F. Weinhold, Chem. Rev. 88, 899 (1988). 
35. W.B. Song, X. Chen, F. Wu, W.J. Tian, Y.G. Ma, H.D. Xu, Chem. J. Chin. Univ. 21, 1422 (2000)

36. J.L. Brédas, R. Silbey, D.S. Boudreaux, R.R. Chance, J. Am. Chem. Soc. 105, 6555 (1983)

37. A. J. Bard, L. R. Faulkner, Electrochemical Methods. Fundamentals and Applications, Wiley, New York. 634 (1984).
38. R. J. Bartlett, I. V. Schweigert, V. F. Lotrich, J. Mol. Struct.: (THEOCHEM) 771, 1 (2006).

39. V.R. Ferro, J.M. García de la Vega, R.H. González-Jonte, L.A. Poveda, J. Mol. Struct.: (THEOCHEM) 537, 223 (2001). 